\title{
SPECIFIC ASPECTS OF ISOTHERMAL AND ANISOTHERMAL FATIGUE OF THE MONOCRYSTALLINE NICKEL-BASE SUPERALLOY CMSX-6
}

\author{
H. Mughrabi, S. Kraft and M. Ott
}

Institut für Werkstoffwissenschaften, Lehrstuhl I,

Friedrich-Alexander-Universität Erlangen-Nürnberg

Martensstrasse 5, D-91058 Erlangen, Federal Republic of Germany

\section{Abstract}

An extensive study of the high-temperature isothermal and thermomechanical fatigue (TMF) behaviour of the "light" nickel-base superalloy CMSX-6 has been performed. Special emphasis was placed on a detailed microstructural interpretation of some specific aspects of the cyclic deformation behaviour. In the case of the isothermal fatigue tests, the main points of interest were the dependence on cyclic strain rate, effects of cyclic softening and directional coarsening, the cyclic stress-strain behaviour, mean stress and cyclic stress asymmetry effects and the dependence of the fatigue behaviour on different initial $\gamma / \gamma^{\prime}$ morphologies. In the TMF tests, the studies focussed on the dependence of fatigue life on the strain-temperature cycle shapes, on directional coarsening effects for different cycle shapes, on the microstructural processes during a single cycle and on the effects of the strongly varying plastic strain rates within a cycle in a total-strain controlled test. A critical comparison between the isothermal and the TMF behaviour permits several conclusions to be drawn. In particular, it follows that while isothermal tests can provide a valuable guideline for the understanding of TMF, they are inadequate for a more detailed interpretation.

\section{Introduction}

Monocrystalline $\gamma^{\prime}$-hardened nickel-base superalloys, exhibiting superior high-temperature strength properties, are nowadays commonly used for advanced turbine blading of aircraft jet engines [1]. High-temperature creep strength and thermomechanical fatigue (TMF) resistance are considered to be the mechanical properties of major concern. While numereous detailed studies on the high-temperature creep behaviour of nickel-base superalloys have been performed in the past, cf. for example [2-7], much less work has been done on the isothermal [8-10] and, in particular, on the anisothermal TMF fatigue properties of monocrystalline superalloys, cf. [11-13]. Knowledge of the isothermal fatigue behaviour can provide a valuable guideline for the understanding of TMF but is, by itself, inadequate in order to deal satisfactorily with the much more complex deformation and damage processes occurring during TMF

The goal of the present work is to gain a deeper understanding of the microstructural processes that govern high-temperature fatigue and, in particular, thermomechanical fatigue, of the "light" monocrystalline nickel-base superalloy CMSX-6. For that purpose, the studies focussed on specific aspects of isothermal fatigue believed to be relevant also to TMF and on the material behaviour under selected well-defined TMF test conditions. The results of these investigations are contrasted against each other, and some general conclusions are drawn.

$$
\text { Superalloys } 1996
$$

\section{Experimental Procedure}

In the present work monocrystalline rods of the $\gamma^{\prime}$-hardened nickel-base superalloy CMSX-6 (composition in wt.\%: $9.76 \mathrm{Cr}$,

$3.01 \mathrm{Mo}, 1.96 \mathrm{Ta}, 4.70 \mathrm{Ti}, 5.23 \mathrm{Co}, 4.81 \mathrm{Al}$, bal. Ni) with orientations that lay within $10^{\circ}$ near [001] were used. These rods had been supplied by Thyssen Guß AG, Feingußwerk Bochum, in the cast and heat-treated state. After machining and electropolishing, the fatigue test specimens had gauge lengths of 12 $\mathrm{mm}$ and a diameter of $9 \mathrm{~mm}$. The microstructure consisted of fairly regularly arranged cuboidal $\gamma^{\prime}$ particles with $470 \mathrm{~nm}$ edge length, occupying a volume fraction of $\geq 0.55$. The constrained misfit parameter was determined by high-resolution X-ray diffraction as $\delta \approx-10^{-3}$.

The fatigue tests were performed on uncoated specimens on a servohydraulic test machine (MTS 880) that had been equipped with high frequency induction coil heating and programming facilities for thermomechanical fatigue tests [14]. A high-vacuum chamber permitted tests in either air, arbitrary gaseous environments or in high vacuum. The isothermal and anisothermal fatigue tests in this study were all performed in closed-loop total strain control at prescribed total strain range $\Delta \varepsilon_{t}$. The corresponding plastic strains $\varepsilon_{p l}$ could be calculated in all cases by taking into account the (tempcrature dependent) clastic strains, determined via the temperature-dependent Young's moduli. The latter had been measured previously in the testing machine.

The TMF-tests were performed with in phase (IP), out-ofphase (OP) and clockwise and counterclockwise diamond (CD, CCD) temperature-total strain cycles. These cycle shapes are shown in plots of temperature $T$ versus total strain $\varepsilon_{t}$ in fig. 1. In general, a total strain range of $\Delta \varepsilon_{t}=10^{-2}$, an upper temperature of $1100^{\circ} \mathrm{C}$ (or in some cases $900{ }^{\circ} \mathrm{C}$ ) and a lower temperature of $600^{\circ} \mathrm{C}$ were used. The cycle time was $t_{c}=300 \mathrm{~s}$, resulting in a tota ${ }^{1}$ strain rate $\dot{\varepsilon}_{t}=6.67 \cdot 10^{-5} \mathrm{~s}^{-1}$. The tests were always started at zero strain at the lowest possible temperature. For further details, see $[15,16]$.

\section{Experinuental Results and Discussion}

\subsection{Isothermal Fatigue}

In the following we report and discuss some noteworthy features of the isothermal fatigue behaviour.

3.1.1 Cyclic Deformation Behaviour Cyclic deformation curves obtained at different temperatures between $950^{\circ} \mathrm{C}$ and $1100{ }^{\circ} \mathrm{C}$ and at $\Delta \varepsilon_{t}=10^{-2}, \tilde{\varepsilon}_{t}=5 \cdot 10^{-3} \mathrm{~s}^{-1}$, are displayed in fig. 2 in the form of peak tensile and compressive stresses versus the num- 
ber of cycles $N$ (fig. 2a) and mean stress amplitude $\Delta \sigma / 2$ and mean stress $\sigma_{m}$ versus $N$ (fig. $2 \mathrm{~b}$ ), respectively. As expected, the stress levels decrease with increasing temperature. At the same time, the fatigue lives decrease, mainly as a consequence of the increasing oxidation. An interesting effect is found with regard to the mean stresses $\sigma_{m}$, which develop during cyclic deformation. Up to $1050^{\circ} \mathrm{C}$, these mean stresses are compressive; at the highest temperature investigated $\left(1100^{\circ} \mathrm{C}\right)$, a tensile mean stress is measured. These results indicate a cyclic stress asymmetry which changes sign around $1075^{\circ} \mathrm{C}$. We return to stress

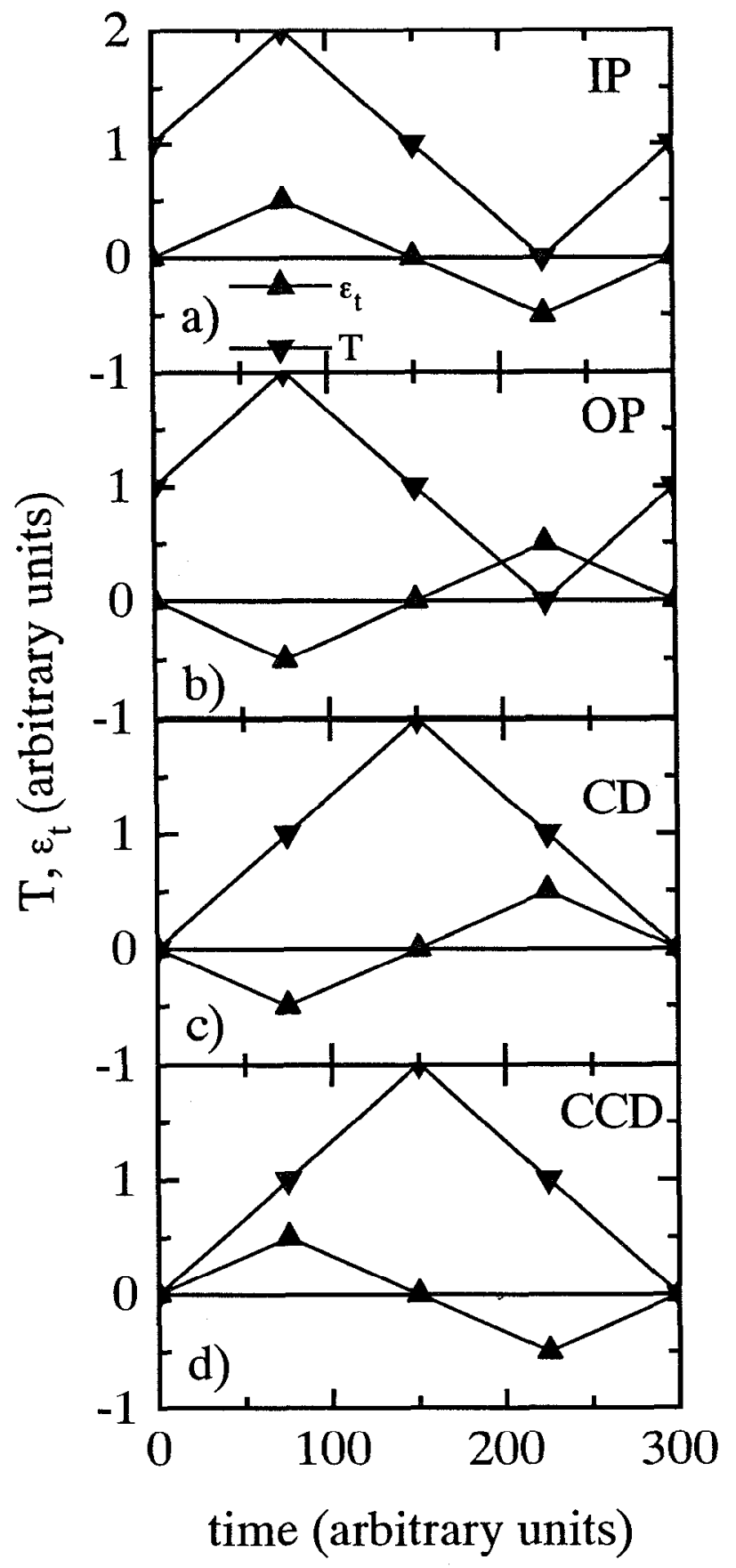

Figure 1: Temperature $T$ and total strain $\varepsilon_{t}$ versus time $t$ for different TMF cycle shapes. a) In-phase TMF (IP); b) Out-ofPhase TMF (OP); c) Clockwise diamond TMF (CD); d) Counterclockwise diamond TMF (CCD).

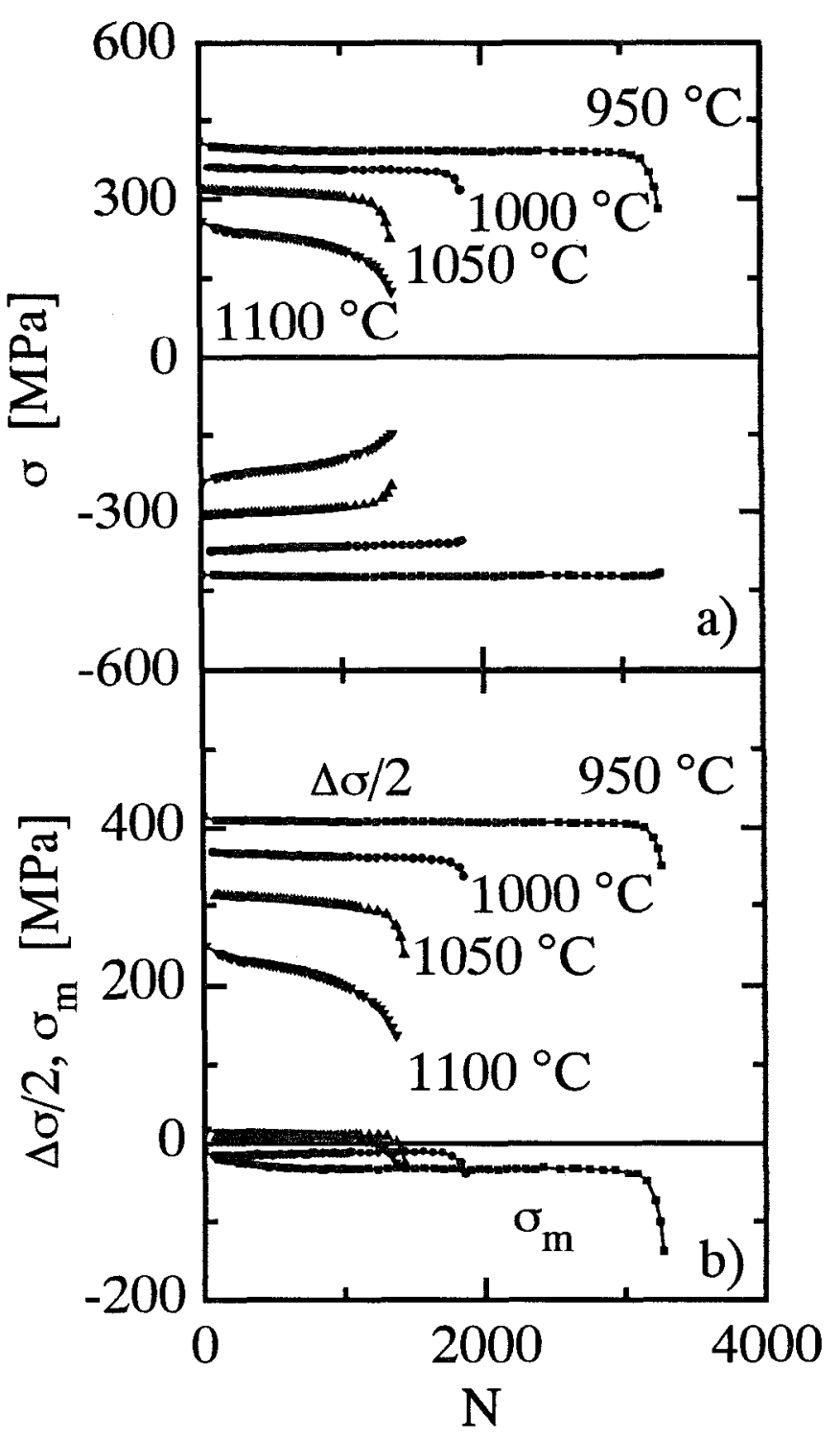

Figure 2: Isothermal cyclic deformation curves for different temperatures. a) Tensile and compressive peak stress $\sigma$ versus number of cycles, $N$; b) Mean stress amplitude $\Delta \sigma / 2$ and mean stress $\sigma_{m}$ versus number of cycles, $N$.

asymmetry effects again in section 3.1.5.

3.1.2 Dependence of the Cyclic Deformation Behaviour on CycIic Strain Rate The effect of cyclic strain ratc on the cyclic deformation behaviour was studied at a temperature of $1100{ }^{\circ} \mathrm{C}$ at $\Delta \varepsilon_{t}=10^{-2}$ for the total strain rates $\dot{\varepsilon}_{t}$ of $6.67 \cdot 10^{-5} \mathrm{~s}^{-1}$ and $5 \cdot 10^{-3} \mathrm{~s}^{-1}$. Figure 3 shows some corresponding hysteresis loops. Due to the enhanced strain-rate sensitivity at high temperatures, the peak stress at the higher strain rate was initially about $25 \%$ higher than at the lower strain rate. In addition, very severe cyclic softening related to a "directional coarsening" of the $\gamma / \gamma^{\prime}$ microstructure was observed at the lower but not at the higher strain rate, compare fig. 4a. As a consequence of these effects, the elastic strain amplitude was much larger at the higher strain rate and hence the plastic strain amplitude significantly smaller than at the lower strain rate. Accordingly, in the sense of a Manson-Coffin-type behaviour, fatigue life was 


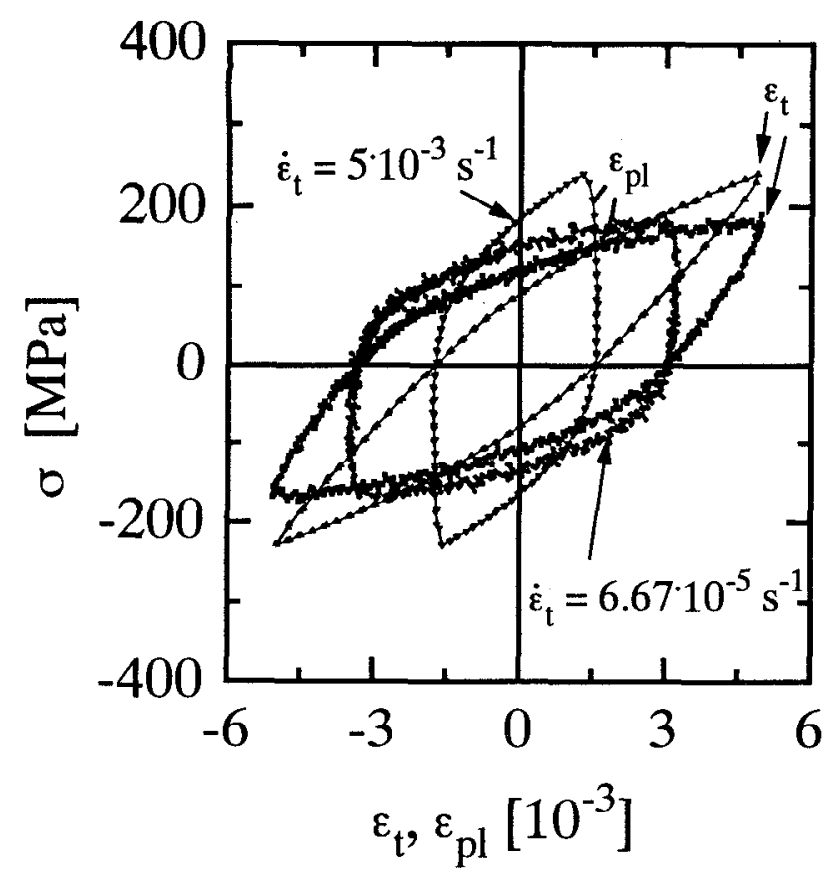

Figure 3: Hysteresis loops at $T=1100^{\circ} \mathrm{C}$ and total strain range $\Delta \varepsilon_{t}=10^{-2}$ for two total strain rates $\dot{\varepsilon}_{t}$ in the form of stress $\sigma$ versus total strain $\varepsilon_{t}$ and plastic strain $\varepsilon_{p l}$. The loops correspond to $N=10$ (low strain rate) and $N=200$ (high strain rate).

significantly larger at the higher than at the lower strain rate. We shall return to the coarsening effects in the next section.

3.1.3 Effects of "Directional" Coarsening at Low Cyclic Strain Rate It is well known that coarsening of the $\gamma / \gamma^{\prime}$ microstructure can occur during deformation at sufficiently high temperature. In the case of the superalloy $\mathrm{SRK} 99$, it has been shown $[8,9]$ that, whereas during fatigue at $950^{\circ} \mathrm{C}\left(\Delta \varepsilon_{t}=1.2 \cdot 10^{-2}\right)$ at a relatively high total strain rate $\left(\dot{\varepsilon}_{t}=10^{-3} \mathrm{~s}^{-1}\right)$, coarsening effects are negligible, severe coarsening leading to an inclined raft-like $\gamma / \gamma^{\prime}$ structure, accompanied by pronounced cyclic softening and reduced fatigue life, occurs al a lower strain rate $\left(\dot{\varepsilon}_{t}=10^{-5} \mathrm{~s}^{-1}\right)$. In our own studies at a rather high temperature $\left(1100^{\circ} \mathrm{C}\right)$, compare fig. 4, qualitatively similar results were obtained. Some coarsening of the initially cuboidal $\gamma^{\prime}$ precipitates (fig. 5a) was observed even after fatigue at the higher strain rate, with a tendency of raft formation perpendicular to the stress axis (fig. 5b), presumably in response to the positive mean stress. The changes in the $\gamma / \gamma^{\prime}$ microstructure after fatigue at the lower strain rate were more pronounced, both with regard to the amount of coarsening and with respect to the change of the morphology (fig. 5c). The edges of the coarsened $\gamma^{\prime}$ precipitates were found to lie more or less parallel to the traces of the $\{111\}$ glide planes. Thus, "soft" $\gamma$-channels had developed along the glide planes. In the related work of Portella et al. $[8,9]$, these soft $\gamma$-channels were even more extended.

It is interesting to discuss to what extent this kind of directional coarsening is induced by annealing at the high temperature and/or the deformation process. In order to be able to perform the comparison for larger times, an additional test was conducted in vacuum at the higher strain rate, and the data were also used. The results shown in fig. 4 a, plotted in the form of the cyclic stress amplitude against time (rather than against the number of cycles) for the two cyclic strain rates, compare fig. $4 \mathrm{~b}$, sheds some light on this question. As expected, the inilial stress amplitude at the lower strain rate is lower than that at the higher strain rate. What seems surprising, is that the subsequent softening (decrease of stress amplitude as a function
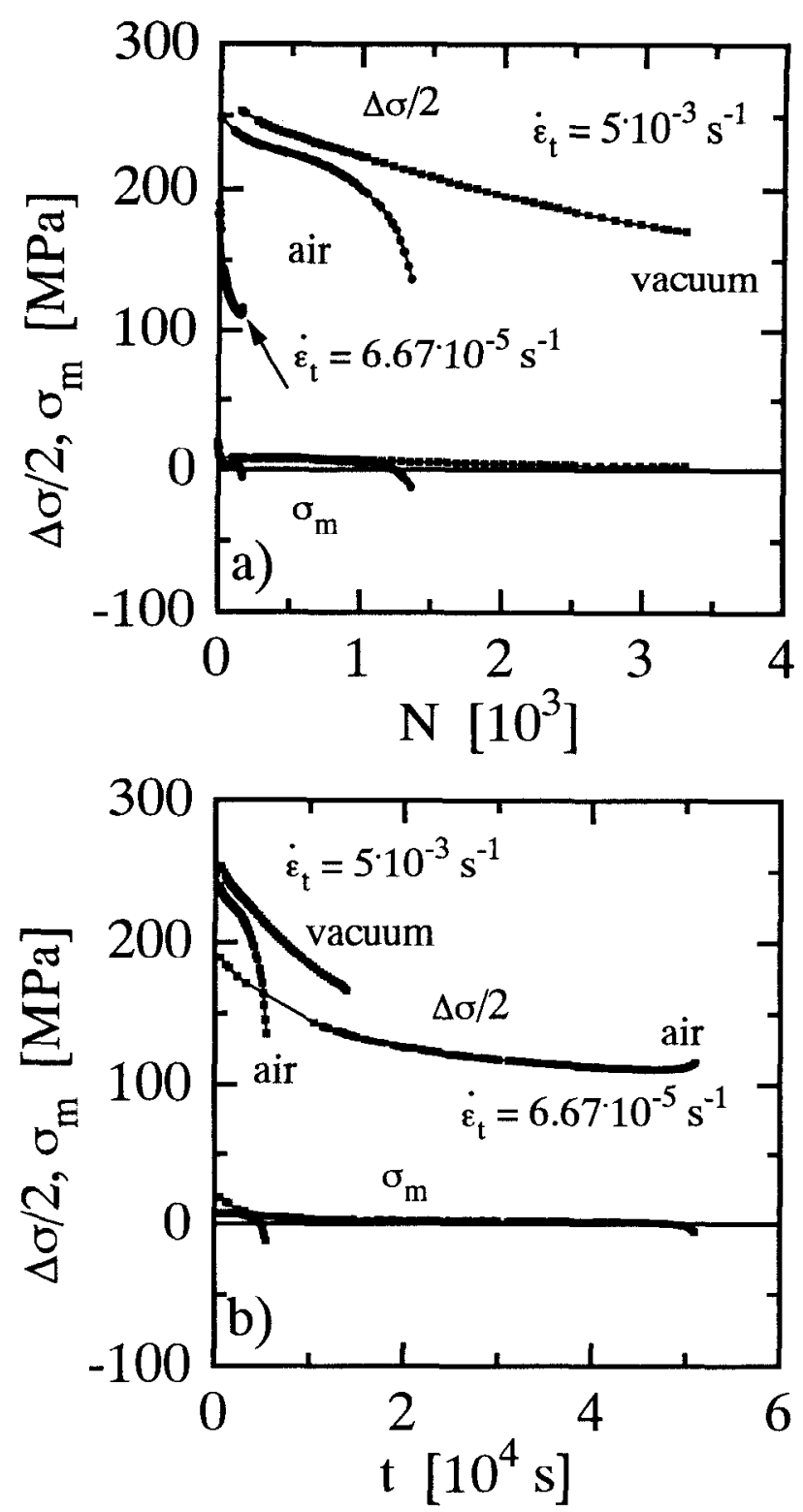

Figure 4: Cyclic hardening curves at $T=1100{ }^{\circ} \mathrm{C}$ and total strain range $\Delta \varepsilon_{t}=10^{-2}$ for two total strain rates $\dot{\varepsilon}_{t}$. The test at the higher strain rate was performed in air and also in vacuum. Mean stress amplitude $\Delta \sigma / 2$ and mean stress $\sigma_{m}$ versus a) number of cycles $N$, and b) the time $t$.

of time) is comparable for the two strain rates. In fact, the rate of softening is even somewhat larger for the higher strain rate. This suggests that, in both cases, the time of exposure to the high temperature is important in promoting the coarsening process, but that, in addition, the amount of strain accumulated during that time also supports the coarsening process, leading to a slightly larger softening rate at the higher strain rate.

3.1.4 Cyclic Stress-Strain Behaviour The cyclic stress-strain behaviour, was studied in a multiple step test $\left(5 \cdot 10^{-3}<\right.$ $\Delta \varepsilon_{t}<2.4 \cdot 10^{-2}$ ) up to plastic strain amplitudes of about $\Delta \varepsilon_{p l} / 2=4 \cdot 10^{-3}$ at $\dot{\varepsilon}_{t}=10^{-2} \mathrm{~s}^{-1}$ at a temperature of $950^{\circ} \mathrm{C}$. A set of typical "saturated" hysteresis loops is shown in fig. 6 . The cyclic stress-strain behaviour exhibits a significant stress asymmetry, the compressive saturation stresses being significantly 


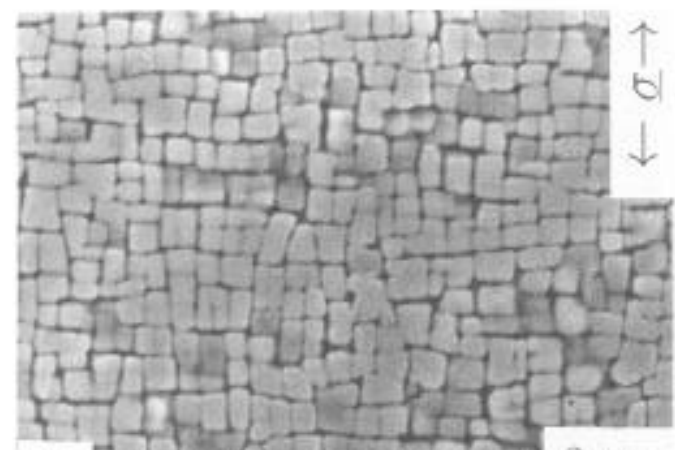

a)
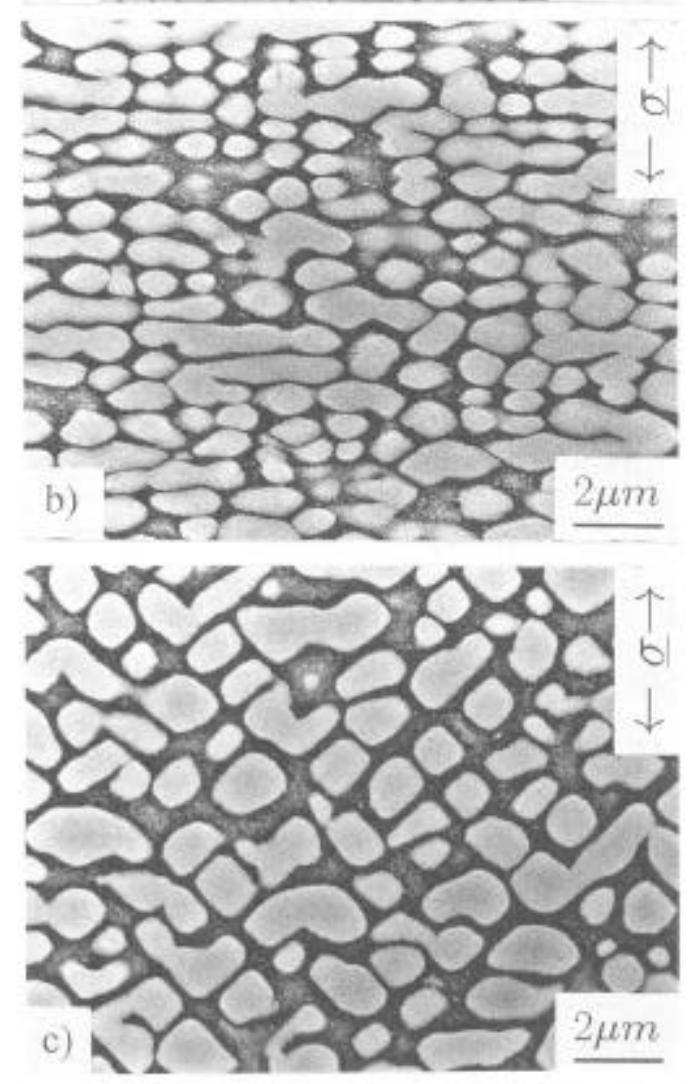

Figure 5: Coarsening of the $\gamma^{\prime}$ precipitates during isothermal fatigue at $T=1100^{\circ} \mathrm{C}, \Delta \varepsilon_{\mathrm{t}}=10^{-2}$. a) Initial $\gamma^{\prime}$ precipitates; b) After fatigue in air at $\dot{\varepsilon}_{1}=5 \cdot 10^{-3} \mathrm{~s}^{-1}$; c) After fatigue in air at $\dot{\varepsilon}_{\mathrm{t}}=6.67 \cdot 10^{-5} \mathrm{~s}^{-1}, \gamma$ etching, the $\gamma$ phase appears dark.

higher than the tensile saturation stresses, in particular in the range $2 \cdot 10^{-3}<\Delta \varepsilon_{n} / 2<3 \cdot 10^{-3}$ as shown in figs. 7 and 8 . This stress asymmetry is in accord with that presented earlier in fig. $2 \mathrm{~b}$ for a comparable temperature.

It should be noted that the bysteresis loops are slightly displaced to positive plastic strains, as shown in fig. 8 for the innermost loop. This is related to the fact that, in the first few cycles, more plastic strain is accumulated in tension than in compression, cf. fig. 9 and section 3.1.5. Since this plastic strain bias toward tension could distort the picture shown in fig. 8 , the data. were also evaluated, using the centre of the inner hysteresis loop as the origin. This procedure reduced the magnitude of the cyclic stress asymmetry somewhat but did not change the essence of the conclusions drawn earlier.

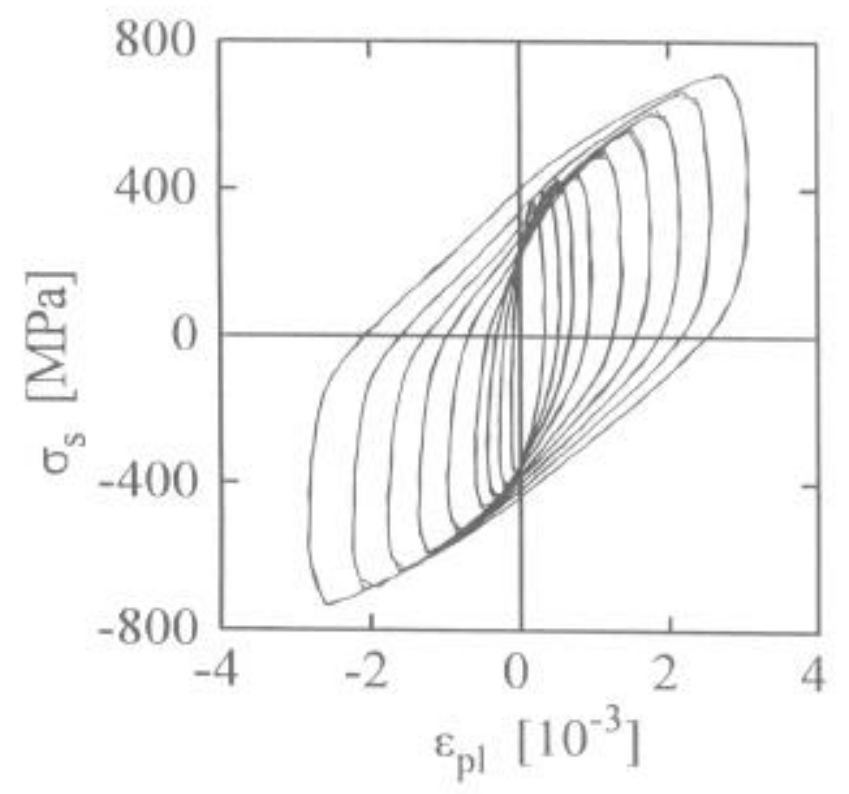

Figure 6: Saturated hysteresis loops measured in a multiple step test at $T=950^{\circ} \mathrm{C}, \dot{\epsilon}_{t}=10^{-3} \mathrm{~s}^{-1}$. Plot of stress $\sigma$ versus plastic strain $\varepsilon_{p i}$.

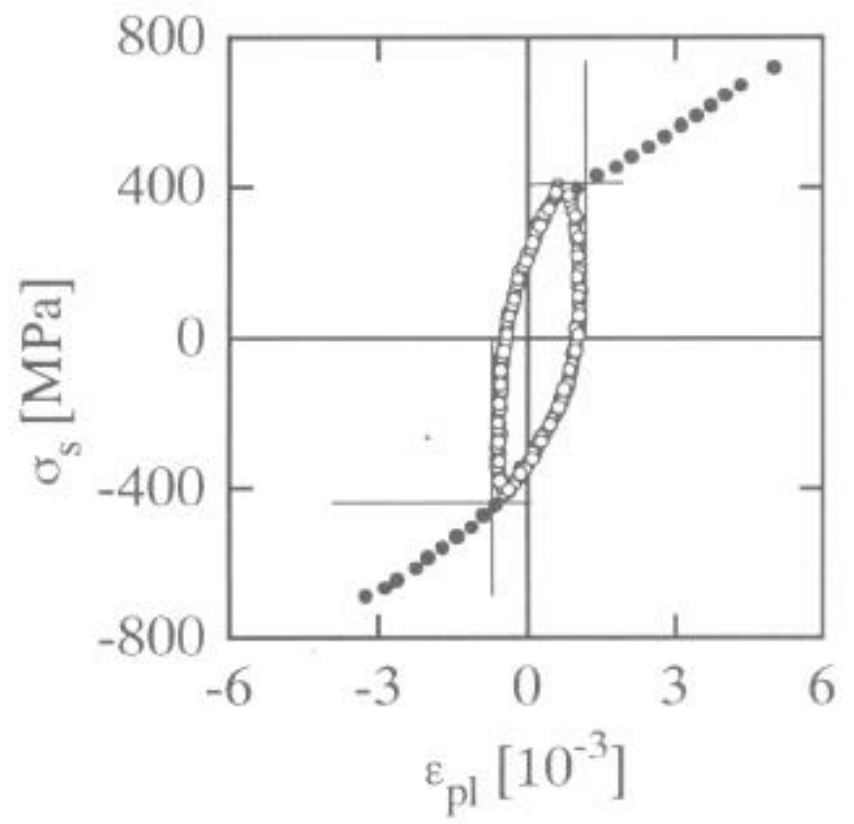

Figure 7: Cyclic stress-strain curves in tension and compression, obtained from hysteresis loops of multiple step test (fig. 6) at $T=950{ }^{\circ} \mathrm{C}$. Plot of saturation stress $\sigma$, versus plastic strain amplitude $\Delta \varepsilon_{\mathrm{pl}} / 2$. The mean value of $\sigma_{g}$ is also plotted.

The shapes of the saturated hysteresis loops shown in fig. 6 differ in the tensile and compressive branches; the tensile branch exhibits a point of inflection in most cases. The same is true for the tensile and compressive cyclic stress-strain curves (fig. 7). In this context, it appears appropriate to point out that, in monotonic tensile testing in the same temperature range, the stressstrain curve consists of several clearly distinguishable stages and also exhibits a point of inflection. Of course, this analogy must be confined to a small range of strain, comparable to that in cyclic deformation. In the case of the monotonic deformation, 


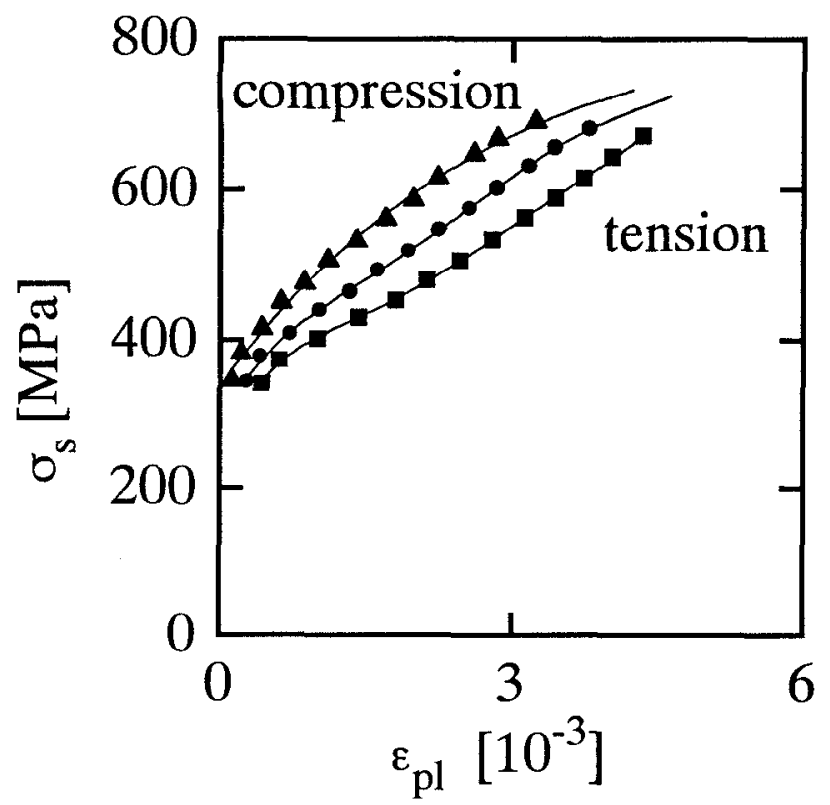

Figure 8: Comparison of cyclic stress-strain curves in tension and compression. Note cyclic stress asymmetry and point of inflection on tensile cyclic stress-strain curve.

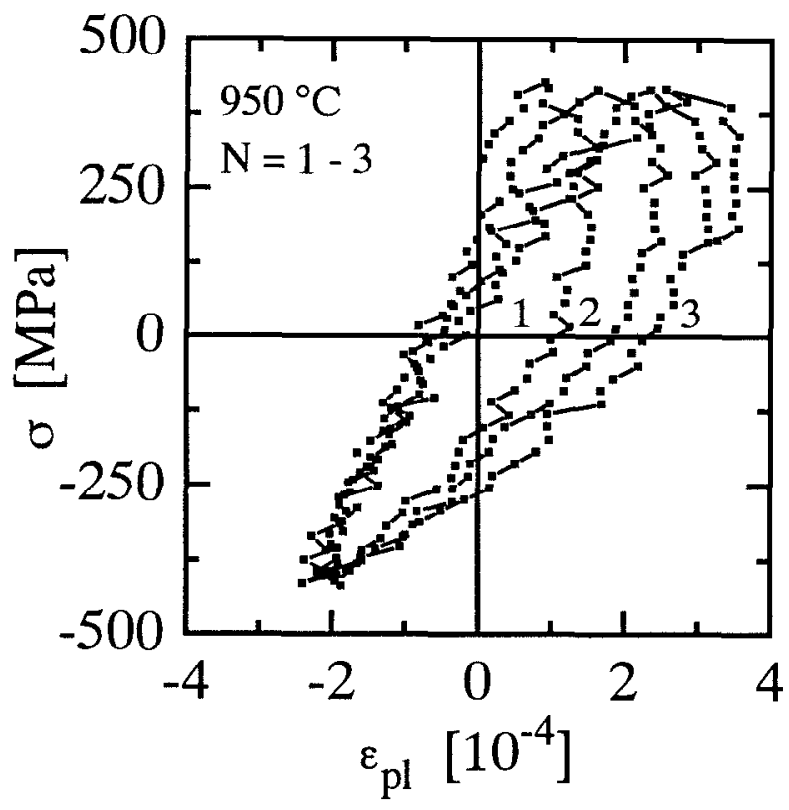

Figure 9: Hysteresis loops for the first 3 cycles at $T=950^{\circ} \mathrm{C}$, $\Delta \varepsilon_{t}=10^{-2}, \dot{\varepsilon}_{t}=5 \cdot 10^{-3} \mathrm{~s}^{-1}$. Note accumulation of tensile plastic microstrain.

the different stages of deformation were related to a sequence of deformation processes in the $\gamma$-channels perpendicular and parallel to the stress axis, respectively, and to cutting of the $\gamma^{\prime}$ precipitates [17].

3.1.5 Cyclic Stress Asymmetry In this section we wish to discuss in a little more detail the effects of cyclic stress asymmetry and inean stress presented earlier (figs. 2, 4, 6, 7 and 8). Three findings are noteworthy with regard to total strain-controlled tests: a) Below a temperature of about $1050^{\circ} \mathrm{C}$ the cyclic stresses are larger in compression than in tension, leading to a negative mean stress.

b) Above that temperature, namely at $1100^{\circ} \mathrm{C}$ in our work, the situation reverses: the tensile stresses now exceed the compressive stresses and a positive mean stress is found.

c) The tensile cyclic stress-strain curve below $1050{ }^{\circ} \mathrm{C}$ exhi bits a point of inflection.

For the cyclic stress asymmetry below $1050{ }^{\circ} \mathrm{C}\left(\sigma_{m}<0\right)$, the cyclic deformation experiments at constant total strain range $\Delta \varepsilon_{t}$ show that more plastic deformation occurs in the tensile half cycles of the first few cycles than in the compressive half cycles. Figure 9 shows an example for $\Delta \varepsilon_{t}=10^{-2}, \dot{\varepsilon}_{t}=5 \cdot 10^{-3} \mathrm{~s}^{-1}$. Here the first three cycles are plotted in the form of stress $\sigma$ against plastic strain $\epsilon_{p l}$. While the plastic strain reached in compression is virtually constant, the tensile plastic strain increases with continued cycling. As a consequence the tensile elastic strain and hence the tensile stress decrease, thus leading to an increased compressive mean stress, in agreement with the results shown in fig. 2. At present, the explanation of the physical origin of the different cyclic stress asymmetries observed below and above about $1050^{\circ} \mathrm{C}$, is not straightforward. TEM studies indicate that dislocation activity in cyclic deformation is confined to the soft $\gamma$-channels. Hence, an explanation must be sought in the mechanisms of dislocation motion in the $\gamma$-channels whose deformation is, however, constrained by the two-phase $\gamma / \gamma^{\prime}$ morphology. For $\gamma^{\prime}$-cuboids, it is expected that, under the combined action of the external stress and the coherency stresses due to a negative lattice mismatch $\delta$, deformation in the tensile and compressive half-cycles occurs preferentially in the $\gamma$-channels that lie perpendicular and parallel to the stress axis, respectively, compare [18]. Such considerations could possibly explain the fact that a point of inflection is found in the lensile but not in the compressive cyclic stress-strain curve. For other $\gamma / \gamma^{\prime}$ morphologies, e.g. raft-like structures, geometric details such as the width of the $\gamma$-channels measured parallel to the glide planes would have to be taken into account. While corresponding detailed calculations are not available at present, it is felt that in order to explain the change of the cyclic stress asymmetry, some additional mechanism must be considered.

3.1.6 Effects of Prerafting on the Fatigue Behaviour Another point of interest concerns the effect of the $\gamma / \gamma^{\prime}$ rafts, which are introduced perpendicular to the stress axis during hightemperature creep, on the fatigue behaviour. Such rafts are also found in turbine blades that have been subjected to service conditions [19]. Lupinc et al. [20] have investigated the effect of $\gamma / \gamma^{\prime}$ rafts that were introduced by prior high-temperature creep on the high-temperature fatigue crack propagation. These authors showed that, for specimens with rafts lying perpendicular to the stress axis, the crack propagation was facilitated, compared to specimens containing cuboidal $\gamma^{\prime}$ precipitates. In order to test the effect of such $\gamma / \gamma^{\prime}$ rafts introduced by high-temperature creep, Ott and Mughrabi [21] carried out isothermal fatigue tests $\left(\Delta \varepsilon_{t}=0.9 \cdot 10^{-2}, T=950^{\circ} \mathrm{C}\right)$ in air on specimens having initially the cuboidal $\gamma^{\prime}$ particle morphology and on other specimens in which $\gamma / \gamma^{\prime}$-raft structures which were either perpendicular or parallel to the stress axis had been introduced by a small $(<0.5$ $\%$ ) prior tensile or compressive creep strain, respectively. These $\gamma / \gamma^{\prime}$ microstructures are shown in fig. 10. Figure 11 shows some results of the fatigue tests. It was found that the fatigue life was enhanced, when the raft structure was parallel to the stress axis. In this case, a deflection of the crack into a direction along the raft structure was obscrved. On the other hand, for the raft structure perpendicular to the stress axis, fatigue life was reduced, and very smooth crack growth was facilitated perpendicular to the stress axis, as found also by Lupinc el al. [20]. In high vacuum, the fatigue lives were generally larger by a factor of about two. Otherwise, similar results were obtained. 


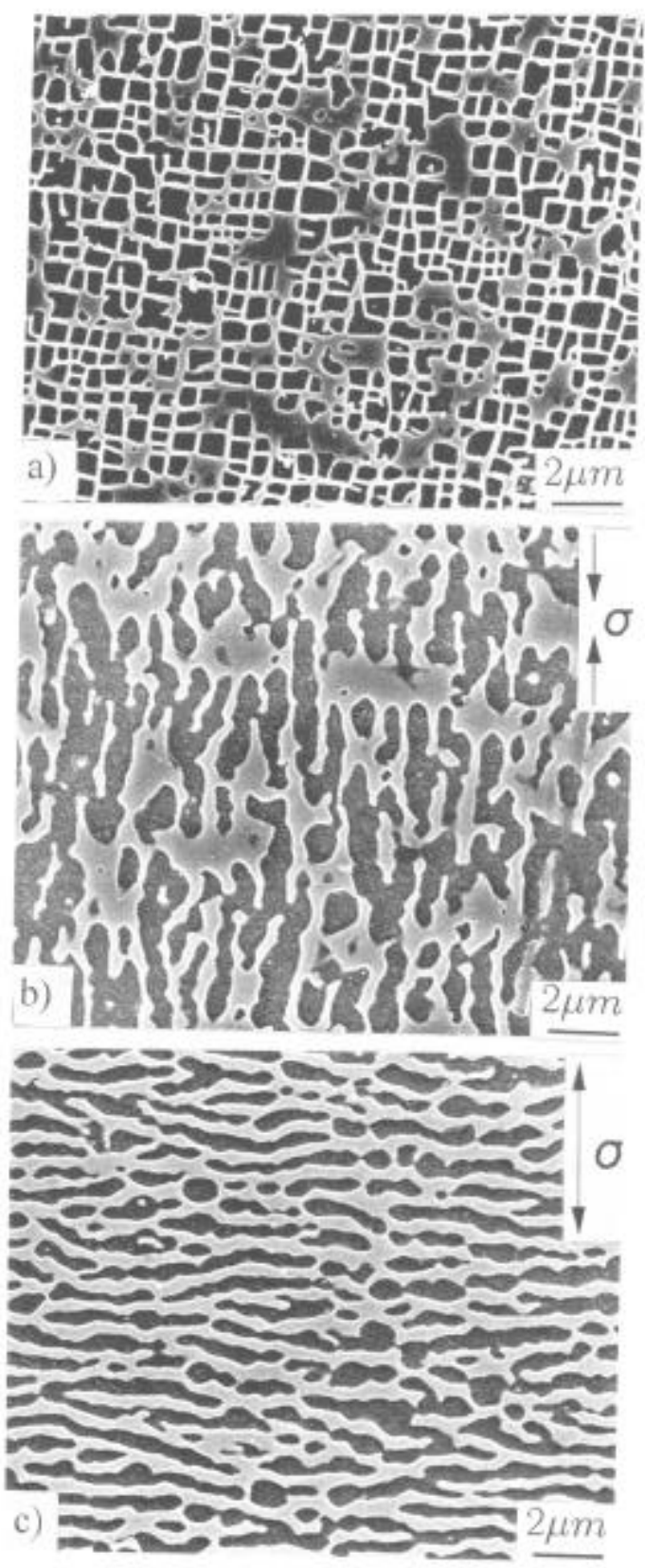

Figure 10: Different $\gamma / \gamma^{\prime}$ microstructures of fatigue samples, a) Initial cuboidal $\gamma^{\prime}$ precipitates; b) $\gamma / \gamma^{\prime}$ raft structure parallel to stress axis after small compressive creep strain at $T=1050$ ${ }^{\circ} \mathrm{C}$; c) $\gamma / \gamma^{\prime}$ raft structure after small tensile creep strain at $T=$ $1050^{\circ} \mathrm{C}, \gamma^{\prime}$ etching, the $\gamma^{\prime}$ phase appears dark.

Figure II shows also that in the predeformed specimens mean stresses $\sigma_{m}$ develop in the direction of predeformation. While these mean stresses can also affect fatigue life in the sense ob. served, it is felt on the basis of the studies of the modes of crack propagation that the microstructural effects described above are dotrinant.

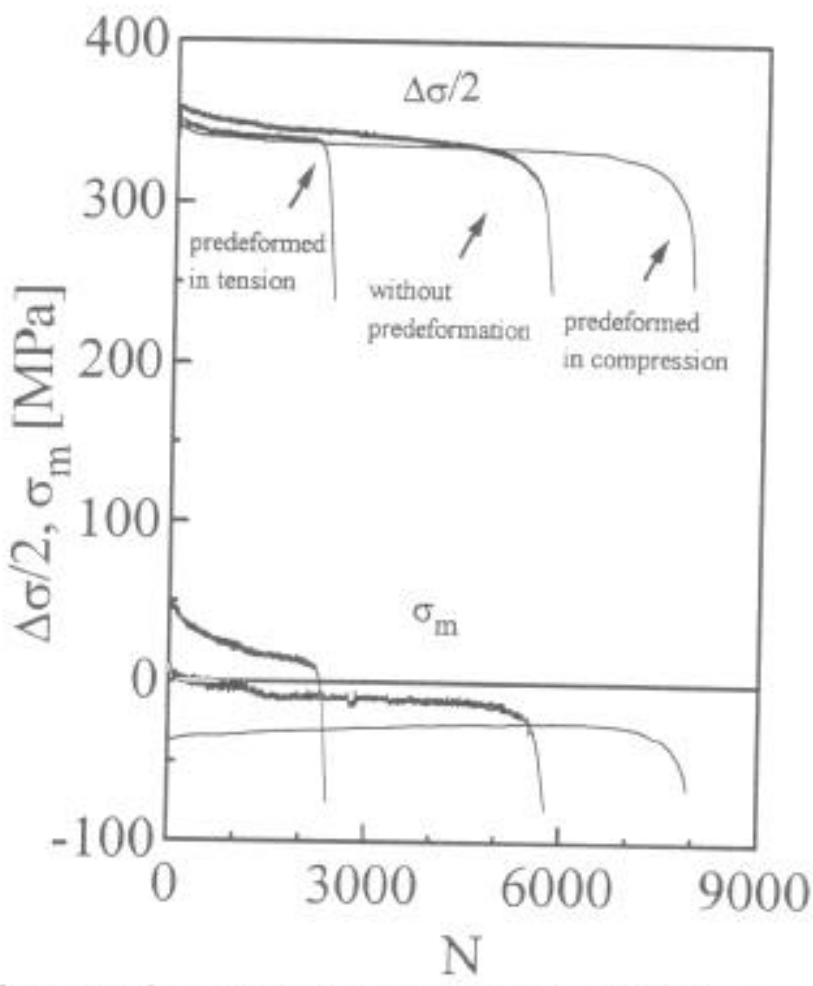

Figure 11: Cyclic deformation curves at $T=950^{\circ} \mathrm{C}, \Delta \varepsilon_{t}=$ $0.9 \cdot 10^{-2}, \varepsilon_{t}=0.9 \cdot 10^{-2} \mathrm{~s}^{-1}$ of specimens with the $\gamma / \gamma^{\prime} \mathrm{mi}-$ crostructures shown in fig. 10 . Plots of mean stress amplitude $\Delta \sigma / 2$ and mean stress $\sigma_{\mathrm{m}}$ versus the number of cycles $N$.

\subsection{Anisothermal Thermomechanical Fatigue}

3.2.1 Cyclic Deformation, Fatigue Lives Figure 12 summarizes the TMF deformation behaviour for an upper temperature of 1100 ' $\mathrm{C}$ in plots of the tensile and compressive peak stresses (fig. $12 \mathrm{a}$ ) and the mean stress amplitude $\Delta \sigma / 2$ versus the number of cycles (fig. 12b).

Out-of phase (OP) TMF leads to the shortest fatigue lives, in phase (IP) TMF to the longest; diamond cycles (CD, CCD yield intermediate fatigue lives. The explanation is based on the fact that fatigue failure was found to occur predominantly by mechanical shear, favoured by large tensile stresses. In OP (IP) tests, a significant tensile (compressive) mean stress develops, and the tensile stresses are hence largest (smallest), the tensile peak stress being reached at the lower (upper) temperature. In the following, emphasis will be laid on the results of the OP TMF cycle shape which is considered to be the most damaging cycle shape in the present study.

3.2.2 Directional Coarsening, Effects on Fatigue Life In OP TMF tests with an upper temperature of $900^{\circ} \mathrm{C}$ (lower tem. perature $600^{\circ} \mathrm{C}$ ) only a very small plastic strain amplitude developed. Failuxe occurred predominantly by local mechanical shear. SEM showed that the cuboidal $\gamma^{\prime}$ particle shape had been completely preserved. In all other TMF tests with upper temperatures of $1100^{\circ} \mathrm{C}$, directional coarsening was observed, leading to more or less well developed $\gamma / \gamma^{\prime}$ raft structures perpendicular (IP, CCD) or parallel (OP, CD) to the stress axis 22]. Examples of the $\gamma / \gamma^{\prime}$ raft structure found for the IP and the OP TMF tests are shown in fig. 13. The orientation of the rafts perpendicular (parallel) to the stress axis in the IP (OP) tests is as expected in the sense that, at the high temperature at which coarsening occurs, the specimen is under a tensile (compressive) stress. 


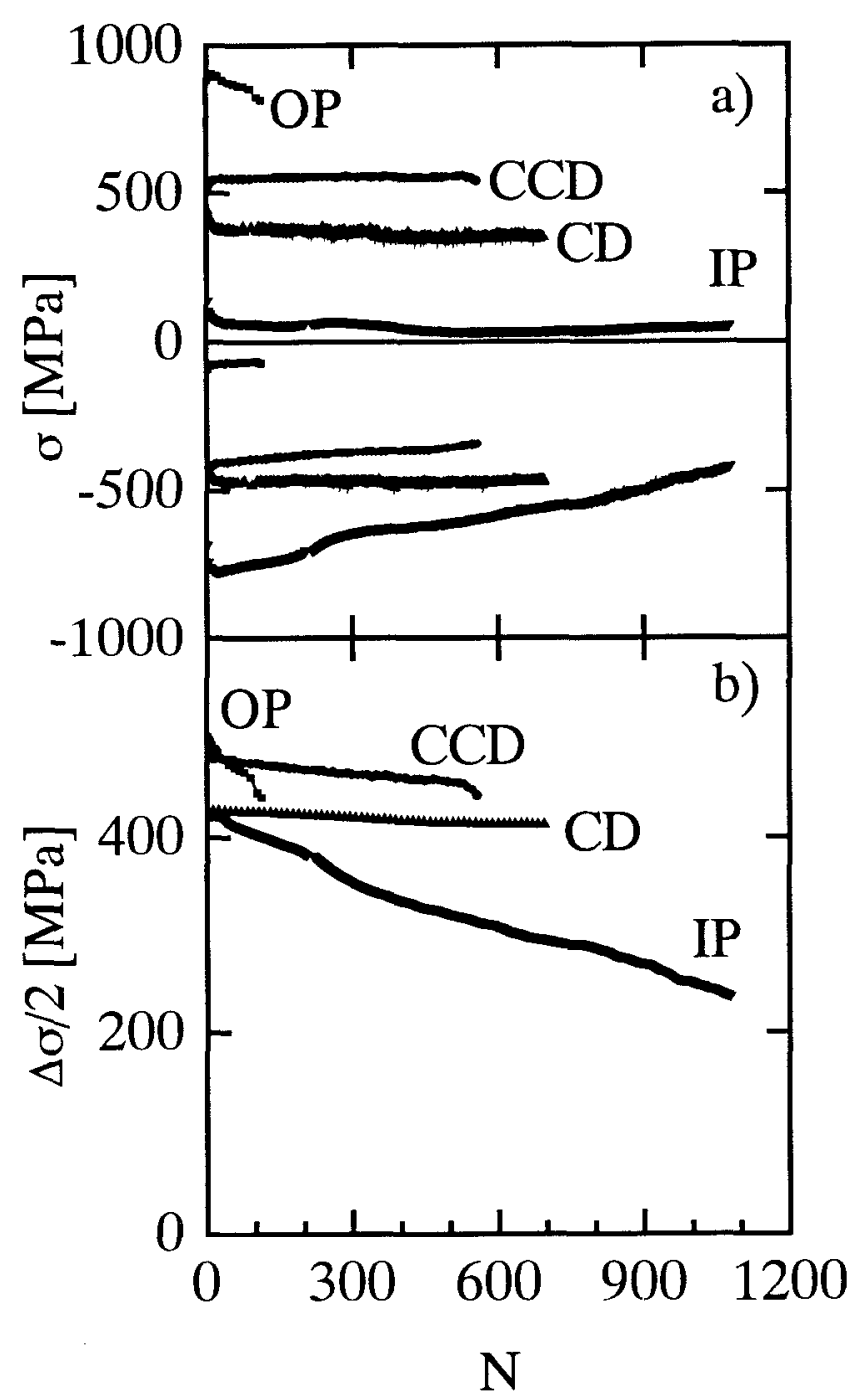

Figure 12: Cyclic deformation curves of TMF tests with different cycle shapes (IP. OP, CD, CCD) for upper and lower temperatures of $1100^{\circ} \mathrm{C}$ and $600^{\circ} \mathrm{C}$, respectively, for $\Delta \varepsilon_{t}=10^{-2}$, $\dot{\varepsilon}_{t}=6,67 \cdot 10^{-5} \mathrm{~s}^{-1}$.

It would, of course, be interesting to know whether these raft structures affect fatigue life and, if so, in what manner. For that purpose, specifically designed TMF tests would have to be performed on specimens with different well defined initial $\gamma / \gamma^{\prime}$-microstructures. The observation of a particular $\gamma / \gamma^{\prime}$ rafi structure in a specimen that has exhibited an extended or reduced TMF life does not permit the conclusion that TMF life was enhanced or reduced by the formation of this paticular $\gamma / \gamma^{\prime}$ raft structure. Thus, Engler-Pinto Jr. et al. [23] found that, in SRR 99, specimens subjected to a so called thermal-fatiguebased (TFB) cycle, a well-developed raft structure was formed parallel to the stress axis and that the TFB fatigue life was larger than that observed after OP TMF or thermal fatigue. They concluded that a raft structure parallel to the stress axis seems to have a beneficial effect on the TMF life. On the other hand, the results of Kraft et al. obtained on the alloy CMSX-6 [21], as shown in figs. 12 and 13, show clearly that, in their work, fatigue life was shortest for the OP TMF test during which a raft structure developed parallel to the stress axis and longest for the IP TMF test which led to a raft structure perpendicular to the stress axis. In other words, these results simply show
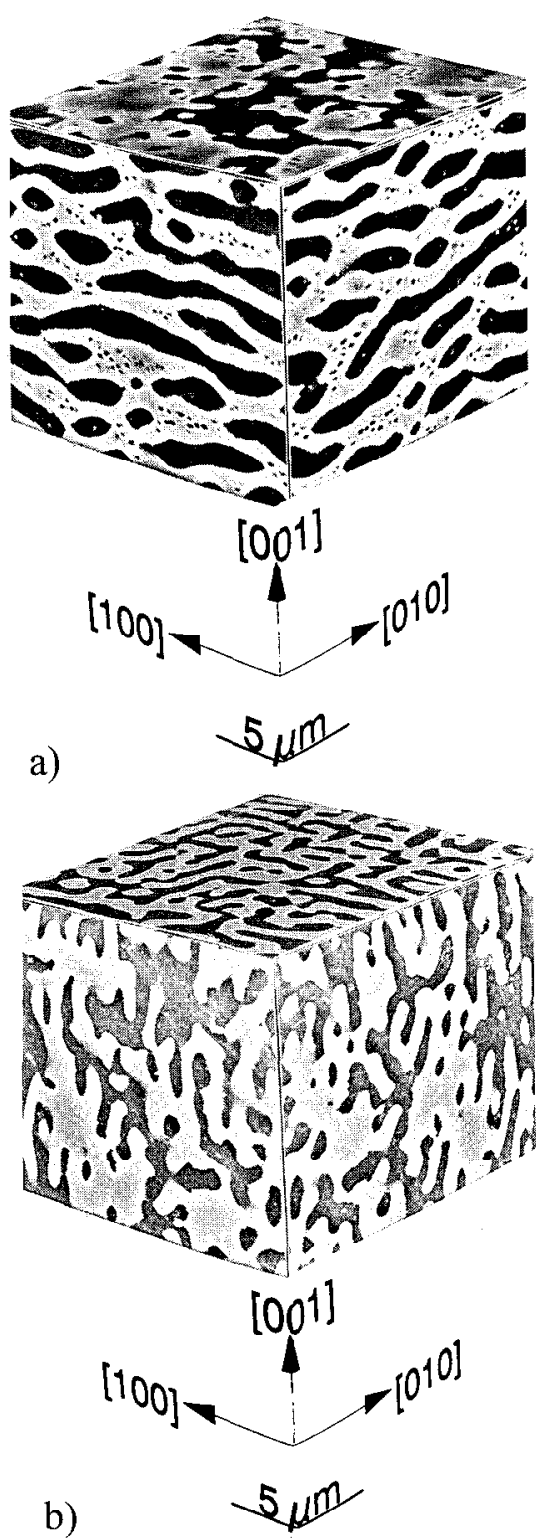

Figure 13: Directionally coarsened $\gamma / \gamma^{\prime}$ raft structures after IP and OP TMF, cf. fig. 12. a) IP; b) OP.

that the raft structures observed after anisothermal fatigue are a consequence of the type of anisothermal fatigue test performed but provide no unequivocal evidence un whether and how these raft structures affect anisothermal fatigue life. Thus, in the OP TMF tests discussed previously, any beneficial effect that the raft structure parallel to te stress axis may have had (compare, for example, the beneficial effect discussed earlier for isothermal fatigue), was obviously more than compensated by the damaging effect of the high tensile stress during the cold phase of the OP TMF cycle.

3.2.3 Microstructural Processes During a Single Cycle Valuable insight into the processes during a single TMF cycle is gained by following the course of stress $\sigma$, plastic strain $\varepsilon_{p l}$ and temperature $T$ versus time $t$ during one cycle, see fig. 14 . In TMF $\mathrm{OP}$ tests with an upper temperature of $900^{\circ} \mathrm{C}$, the shape of the stress-strain hysteresis loop is complex, and the plastic strain is barely measureable, as shown in fig. $14 \mathrm{a}$, for cycles number 1 , 100 and 500 . Nontheless, there is a cumulative accumulation of 


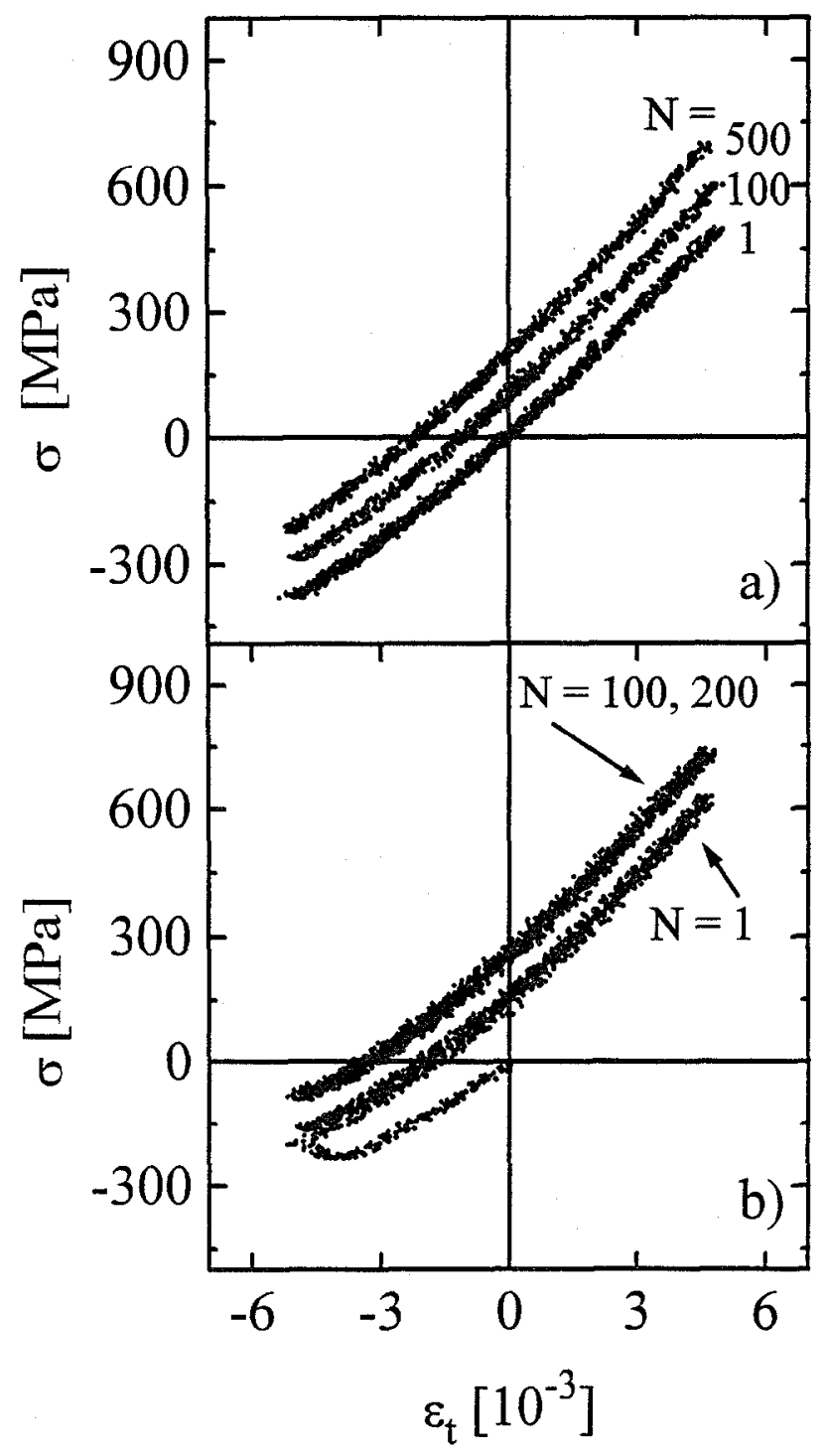

Figure 14: Single OP TMF cycles, plots of $\sigma$ versus $\varepsilon_{t}$. a) Upper temperature $T=900^{\circ} \mathrm{C}$, cycle number 1,100 and $500 ; b$ ) Upper tempcrature $T=1100^{\circ} \mathrm{C}$, cycle number 1,100 and 200 .

very small cyclic microplastic strains in the sense that, within 100 cycles, a permanent negative strain of about $-1 \cdot 10^{-3}$ develops, accompanied by the build-up of a tensile mean stress of $150 \mathrm{MPa}$. No further changes are measurable up to $500 \mathrm{cy}$ cles. In TMF OP tests with an upper temperature of $1100^{\circ} \mathrm{C}$ (fig. 14b), significant microplastic yielding in compression and the development of an appreciable tensile mean stress seem to occur in the hot phase during the first quarter cycle. After 100 cycles, the specimen has suffered a permanent negative plastic strain of about $-3 \cdot 10^{-3}$ and has acquired a tensile mean stress of about $300 \mathrm{MPa}$. No significant further changes occur within the next 100 cycles.

\subsubsection{Variation of Cyclic Plastic Strain Rate During a Cycle}

We now discuss the changes of the plastic strain rate $\dot{\varepsilon}_{p l}$ within an OP TMF cycle. The corresponding hysteresis loop is shown in fig. 15a. For a triangular linear $\varepsilon_{t}(t)$ course, the $\varepsilon_{p l}(t)$ course is strongly non-linear, compare fig. $15 \mathrm{~b}$. As a consequence, the instantaneous plastic strain rate $\dot{\varepsilon}_{p l}$ (slope of $\varepsilon_{p l}$ ) changes continuously, being close to zero most of the time and approaching, in
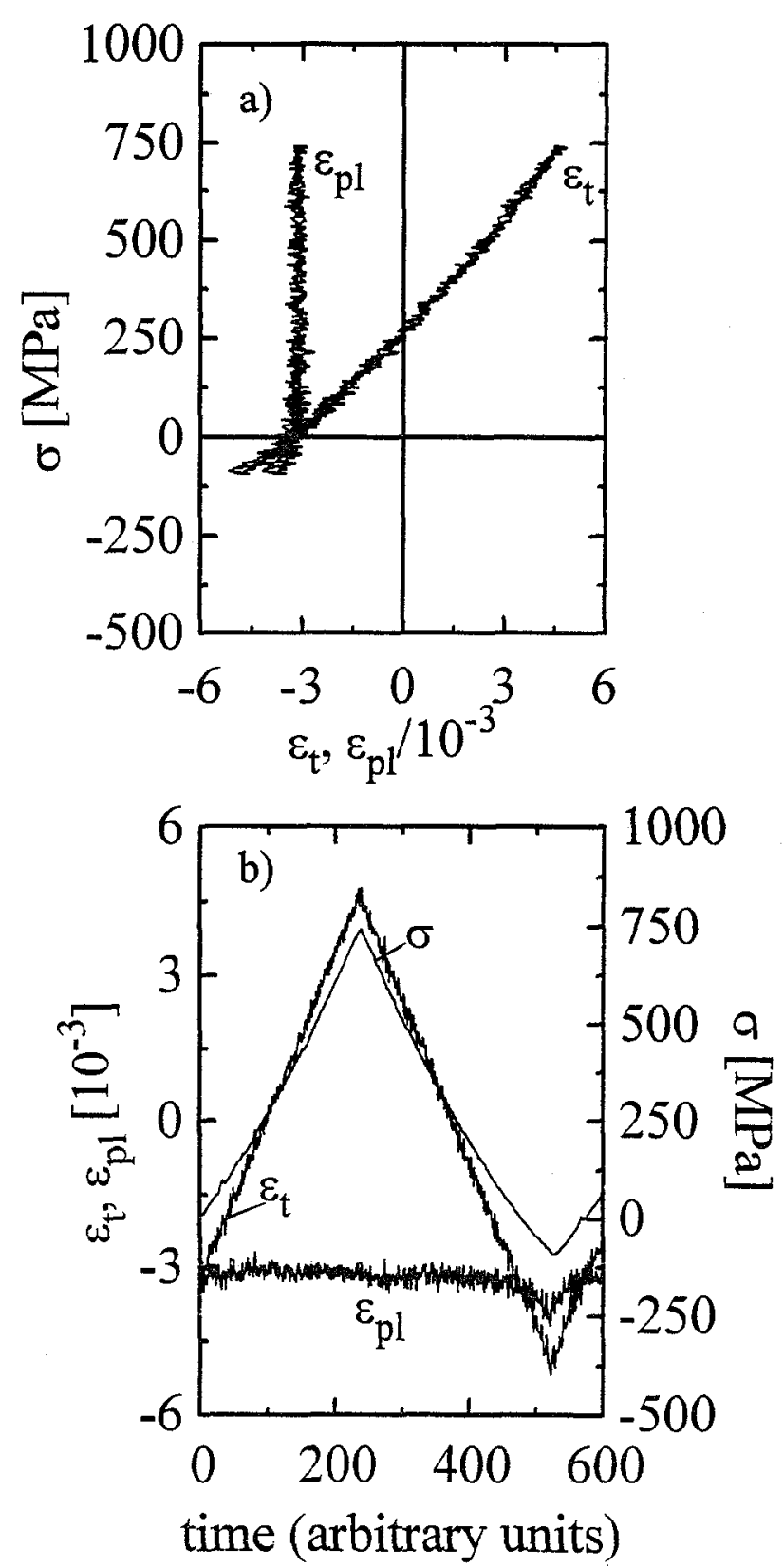

Figure 15: OP TMF test, as in fig. 12. a) Hysteresis loop, plot of stress $\sigma$ versus total strain $\varepsilon_{t}$ and versus plastic strain $\varepsilon_{p l} ; \mathrm{b}$ ) Plot of stress $\sigma$, total strain $\varepsilon_{t}$ and plastic strain $\varepsilon_{p l}$ versus time $t$ within one cycle.

the case of an OP TMF test, a significant value only during microyielding in the approach to the maximum temperature in the compression phase [14]. This variation of instantaneous plastic strain rate within a cycle is more severe than during isothermal fatigue. A detailed discussion of these effects has been given recently [14]. Some consequences are as follows. In a typical TMF test on a bulk specimen, the cycle time is in the order of several 100 seconds. Thus, the mean cyclic strain rate is very low, beeing significantly less then $10^{-4} \mathrm{~s}^{-1}$ for the mean total strain rate $\dot{\varepsilon}_{t}$ and another one or two magnitudcs lower for the mean plastic strain rate $\dot{\varepsilon}_{p l}$. As shown for the isothermal tests, compare figs. 4 and 5 , the cyclic deformation behaviour for very low strain rates differs significantly from that at higher strain rates and leads to drastic coarsening and softening effects. Thus, a. comparison of the cyclic deformation of TMF tests with data 
obtained in typical thermal fatigue tests on wedge-shaped specimens with much shorter cycle times is problematic. Further complications arise from the fact that the damage mechanisms and the process of crack propagation are quite different in the two cases, compare [24]. One step to improve the comparability would be to perform the TMF tests on hollow specimens in the hope to increase the strain rate by about one order of magnitude, compare [25]. Such work is in progress.

\section{Conclusions}

On the basis of the conducted experiments and, in particular, by a comparison of the results observed for isothermal and for anisothermal thermomechanical fatigue, several conclusions can be drawn. Here we note:

a) There are fundamental differences between isothermal and anisothermal fatigue behaviour. Hence, any similarities must be viewed critically.

b) Directional coarsening of the $\gamma / \gamma^{\prime}$ microstructure is qualitatively different in isothermal and anisothermal fatigue, and even for similar $\gamma / \gamma^{\prime}$ raft structures accompanying changes of faligue lives can be quile different. The nicrostructural effects seem more important in isothermal than in anisothermal fatigue.

c) At high temperatures, drastic cyclic softening, caused by marked coarsening of the $\gamma / \gamma^{\prime}$ microstructure, occurs in particular at low strain rates.

d) In total-strain controlled tests, the instantaneous plastic strain rate varies in a complex manner during a single cycle. Because of the high strain-rate sensitivity at high temperatures, the consequences of such bchaviour deserve more attention.

e) Mean stresses must be considered in both isothermal and anisothermal fatigue, being more important in the latter case.

f) In TMF tests, the temperature changes simultaneously with the mechanical strain. As a consequence, the effects of strain rate are more pronounced than in isothermal tests.

g) In TMF tests on bulk specimens, the cycle times are in the order of minutes, and the (plastic) strain rate is accordingly much lower than in thermal fatigue tests with typical cycle times in the order of seconds. In addition, the nature of fatigue damage is different in both cases. Thus, a direct comparison is problenatic.

\section{Acknowledgements}

This work is supported by the Bundesminister für Bildung, Forschung und Technologie (BMBF) in a collaboration between several institutes and industrial companies under contract number BMFT-MatFo 03M3038F and by the Deutsche Forschungsgemeinschaft under contract number Mu502/8-3. Sincere thanks are expressed to all partners involved in this project, and in particular to Dr. Wortmann and Dipl.-Ing. Buchmann of MTU München, and Dr. Goldschmidt, formerly with MTU, München, now with Siemens AG/KWU, Mühlheim.

\section{References}

1. M. Gell, D.N. Guhl, D.K. Gupta, and K.D. Sheffler, "Advanced Superalloy Foils", Journal of Metals, 39 (1987) 1115.
2. P. Caron and T. Khan, "Improvement of Creep Strength in a Nickel-Base Single Crystal Superalloy by Heat Treatment", Mater. Sci. Eng., 61 (1983) 173184.

3. M.V. Nathal, R.A. MacKay, and R.V. Miner, "Influence of Precipitate Morphology on Intermediate Temperature Creep Properties of a Nickel-Base Superalloy Single Crystal", Metall. Trans., 20A (1989) 133-141.

4. T.M. Pollock and A.S. Argon, "Directional Coarsening in Nickel-Base Crystals with High Volume Fractions of Coherent Precipitates", Acta metall. mater., 42 (1994) 1859-1874.

5. M. Feller-Kniepmeier and T. Link, "Correlation of Microstructure and Creep Stages in the 001$\rangle$ Oriented Superalloy SRR 99 at $1253 \mathrm{~K}^{*}$, Metall. Trans., 20A (1989) 1233-1238.

6. J. Hammer and H. Mughrabi, "High Temperature Creep and Micrustructure of the Monocrystalline Nickel-Basc Supcralloy SRR 99", in Proc. of EUROMAT 1989, eds. H.E. Exner, and V. Schumacher, Vol. 1: Advanced Processing and High Temperature Materials, co-eds. D. Driver, and H. Mughrabi (Oberursel: DGM Informationsgesellschaft, 1990) 445-450.

7. W. Schneider, J. Hammer, and H. Mughrabi, "Creep Deformation and Rupture Behaviour of the Monocrystalline Superalloy CMSX-4 - A Comparison with the Alloy SRR 99", in "Superalloys 1992", eds. S.D. Antolovich et al. (Warrendale, PA: The Minerals, Metals and Materials Society, 1992) 589-598.

8. P.D. Portella, C. Kirimtay, and K. Naseband, "Kriech- und I,CF-Verhalten der einkristallinen Superlegierung SRR 99" in Proc of 13 . Vortragsveranstaltung der AG Hochtemperaturwerkstoffe (Düsseldorf: VDEh, 1990) 145-152.

9. P.D. Portella, A. Bertram, E. Fahlbusch, H. Frenz, and J. Kinder, "Cyclic Deformation of the Single Crystal Superalloy SRR 99 at $980^{\circ} \mathrm{C}^{\prime \prime}$, in Proc. of FATIGUE' '96, May 6-10, 1996, Berlin (Oxford: Elsevier Science Ltd., 1996). In press.

10. T.P. Gabb and G. Welsch, "The High Temperature Deformation in Cyclic Loading of a Single Crystal Nickel-Base Superalloy", Acta mctall., 37 (1989) 2507-1516.

11. E. Fleury and L. Rémy, "Thermal-Mechanical Fatigue Behaviour of AM1 Superalloy Single Crystals" in "High Temperature Materials for Power Engineering", eds. E. Bachelet et al. (Dordrecht, Netherlands: Kluwer Academic Press, 1990) $1007-1016$

12. D. A. Boisimer and H. Sehitoglu, "Thermo-Mechanical Fatigue of MAR-M247", Parts I and II, Trans. ASME, 112 (1990) $68-79,80-89$.

13. J.Y. Guédou and Y. Honnorat, "Thermomechanical Fatigue of Turbo-Engine Blade Superalloys", in "Thermomechanical Fatigue Behavior of Materials", ed. H. Sehitoglu (Philadelphia, PA: American Society for Testing and Materials, ASTM STP $1186,1993) 157-171$.

14. H.J. Christ, H. Mughrabi, S. Kraft, F. Petry, R. Zauter, and K. Eckert, "The Use of Plastic Strain Control in Thermomechanical Fatigue Testing", in Proc. of Int. Symp. on "Fatigue under Thermal and Mechanical Loading - Mechanisms, Mechanics and Modelling“, May 22-24, 1995, Petten, Netherlands, (Dordrecht, Netherlands: Kluwer Academic Press, 1996). In press. 
15. S. Kraft, R. Zauter, and H. Mughrabi, "Aspects of High-Temperatiure Iow-Cycle Thermomechanical Fatigue of a Single Crystal Nickel-Base Superalloy", Fatigue Fract. Engng. Mater. Struct., 16 (1993) 237-253.

16. S.A. Kraft and H. Mughrabi, "Thermomechanical Fatigue of the Monocrystalline Nickel-Base Superalloy CMSX-6", in "Thermo-Mechanical Fatigue Behavior of Materials", 2nd Volume, eds. M.J. Verrilli, and M.G. Castelli, (Philadelphia, PA: American Society for Testing and Materials, ASTM STP 1263, 1996). In press.

17. S. Kraft, "Verformungverhalten und Mikrostruklur der einkristallinen Nickelbasis-Superlegierung CMSX-6 nach isothermer und thermomechanischer Beanspruchung", Doctorate Thesis, Universität Erlangen-Nürnberg, 1996.

18. H. Mughrabi, H. Feng, H. Biermann, "On the Micromechar nics of the Deformation of Monocrystalline Nickel--Base Superalloys", in Proc. of the IUTAM Symposium on "Micromechanics of Plasticity and Dannage of Multiphase Materials", Aug. 29Sept. 1 1995, Sévres, eds. A. Pineau, and A. Zaoui (Dordrecht, Netherlands: Kluwer Academic Press, 1996). In press.

19. S. Draper, D. Hull, and R. Dreshfield, "Observations of Directional Gamma Prime Coarsening During Engine Operation", Metall. Trans., 20A (1989) 683-688.

20. V. Lupinc, G. Onofrio, and G. Vimercati, "The Enect of Creep, Oxidation and Crystal Orientation in High Temperature Fatigue Crack Propagation in Standard and Raft-Like Gamma Prime CMSX-2", in "Superalloys 1992", eds. S.D. Antolovich et al. (Warrendale, PA: The Minerals, Metals and Materials Society, 1992) 717-726.

21. M. Ott and H. Mughrabi, "Dependence of the Isothermal Fatigue Behaviour of a Monocrystalline Nickel-Base Superalloy on the $\gamma / \gamma^{\prime}$ Morphology", in Proc. of FATIGUE '96, May 6-10, Berlin, eds. G. Lütjering, and H. Nowack, (Oxford: Elsevier Science Ltd., 1996). In press.

22. S. Kraft, I. Altenberger, and H. Mughrabi, "Dircctional $\gamma / \gamma^{\prime}$ Coarsening in a Monocrystalline Nickel-Base Superalloy During Low-Cycle Thermomechanical Fatigue", Scripta metall. et mater., 32 (1995) 411-416.

23. C.C. Engler-Pinto Jr., F. Meyer-Olbersleben, and F. RézaïAria, "Thermomechanical Fatigue Behaviour of SRR 99", in Proc. of Int. Symp. "Fatigue under Thermal and Mechanical Loading - Mechanisms, Mechanics and Modelling", May 2224, 1995, Petten, Netherlands (Dordrecht, Netherlands: Kluwer Academic Press, 1996). In press.

24. F. Meyer-Olbersleben, C.C. Engler-Pinto Jr., and F. RézaïAria, "On Thermal Fatigue of Nickel-Based Superalloys", in "Thermo-Mechanical Fatigue Behavior of Materials", 2nd Volume, eds. M.J. Verrilli, and M.G. Castelli, (Philadelphia, PA: American Society for Testing and Materials, ASTM STP 1263, 1996). In press.

25. R. Zauter, H.J. Christ, and H. Mughrabi, "Some Aspects of Thermomechanical Fatigue of AISI 304L Stainless Steel“, Parts I and II, Metall. Trans., 25 (1994) 401-406, 407-413. 